\title{
ALKALI-SILICA REACTIVITY OF PORTLAND-COMPOSITE CEMENTS AND GRAVEL AGGREGATES
}

\author{
JADVYGA ŽVIRONAITE்*, JOLANTA PRANCKEVIČIENE*, MODESTAS KLIGYS*, \\ \#GIEDRIUS BALČIŪNAS*, ARTURS MACANOVSKIS** \\ *Institute of Building Materials, Vilnius Gediminas Technical University, Sauletekio av. 11, Vilnius, LT-10223, Lithuania \\ **Institute of Mechanics, Riga Technical University, 1 Kalku street, Riga, LV-1658, Latvia \\ \#E-mail: giedrius.balciunas@vgtu.lt
}

Submitted October 2, 2018; accepted November 19, 2018

Keywords: Alkali-silica reaction, Supplementary cementing materials, Mortar bar testing, Expansion, Surface damage

The potential alkali-silica reactivity (ASR) of various combinations of Portland-composite cements CEM II/A, and Lithuanian aggregates from three gravel deposits are investigated in this work. These aggregates which contain about (2 - $4 \%)$ reactive siliceous rocks (mostly rapid reacting opal and slower reacting flint) could possibly be assigned to Class II-S (potentially alkali-reactive). Two indicators were used to assess the effectiveness of the supplementary cementing materials (SCMs) slag (S), fly ash (FA) and burnt shale, which are present up to $20 \%$ in the cement: the expansion of the mortar specimens in a hot alkali solution and the intensity of the ASR-caused surface damage in the warm humid environment $\left(60{ }^{\circ} \mathrm{C}\right.$ and $100 \%$ $R H)$. The presence of $S(\sim 15 \%)$ and $F A(10 \%, 15 \%, 20 \%)$ in the cements decreases the expansion, but no mitigating effect (in the case of S) or even a stimulating effect (in the case of $10 \%$ and $15 \%$ FA) was observed for the ASR-caused surface damage, the effect only occurred in the case of the threshold content $(20 \%)$ of FA in the cement. The stimulating effect of burnt shale $(\sim 18 \%)$ was observed on both the expansion and surface damage. A strong linear correlation $(R=0.95)$ between the changes in the flexural strength and expansion was observed in the 28-day specimens when tested according to AAR-2.2.

\section{INTRODUCTION}

The alkali-silica reaction (ASR) is one of the most harmful processes that has a damaging effect on concrete structures. Although this harmful process and ASR prevention has been investigated for more than seven decades, a great number of ASR inducing factors, such as the variety of the globally available aggregates and binder types, the different structure of the reactive minerals, their amount and distribution in the aggregates, the environment specifics, etc. cause a lot of uncertainties or even contradictions. ASR is a family of related reactions that affects different rock types in different ways [1-5] and, accordingly, each region developed a test and preventive measures for the avoidance of these damaging reactions appropriate to its own geology and experience [6-8]. Three successive RILEM Technical Committees had made great efforts in developing harmonised and globally applied test methods and specifications for the avoidance of damaging ASR [9, 10]. A comprehensive set of test methods and specifications are published as RILEM Recommendations and Reports. The European Committee for Standardisation document CEN/TR 16349 [11], which is partly based on the RILEM recommendations, presents the following precautionary measures when a reactive (deleterious) aggregate is used:
- limiting the effective alkali content in the cement and concrete;

- use of supplementary cementing materials (fly ash, slag, etc.) in the cement or as an addition;

- verification of the suitability of a concrete mix in a performance test.

The concrete aggregates from the Lithuania gravel deposits contain about $(2-4 \%)$ reactive silica minerals, mostly rapid reacting opal and a slower reacting cryptocrystalline quartz mineral (flint) [12-14]. The reactivity tests with aggregates from different Lithuanian regions [13] conducted in accordance with the RILEM AAR-2.2 method showed that the majority of the investigated aggregates could possibly be attributed to Class II-S according to the RILEM AAR-0 requirements (potentially alkali-reactive) [15] and their expansion values are most often close to the lower limit value. Although these values demonstrate the relatively low reactivity of the aggregates, ASR was found to be very common in the structures made of concrete containing these aggregates before the introduction of the preventive measures. The low expansion of the specimens with similar type reactive aggregates (gravel with flint) in the AAR-2 test has also been shown in tests carried out according to the framework of the EU project 
PARTNER [7]. No total failure of a structure, such as the collapse of a building, was recorded though in Lithuania. The most common symptoms of the deleterious ASR in structures with Lithuanian aggregates are pop-outs, alkali-silica gel stains, spalling and cracking. These ASR processes cause serviceability problems, and promote other deterioration mechanisms such as freezethaw damage or sulphate attack. The ASR phenomena almost disappeared with the introduction of the preventive measures (limiting the alkali content in the Portland cement CEM I and Portland-composite cement CEM II $(\leq 0.8 \%)$ and of the concrete $\left(3.0 \mathrm{~kg} \cdot \mathrm{m}^{-3}\right.$ and $4.0 \mathrm{~kg} \cdot \mathrm{m}^{-3}$ according to environmental category), except for the occasional occurrence of ASR in structures operated in an E3 environment (according to CEN/TR 16349)). These preventive measures were mainly based on the results of experimental tests (laboratory and in field) with plain Portland cement CEM I. No exhaustive research has been undertaken into the change in resistance to ASR of the structures made from Portland composite cement CEM II/A which can contain up to $20 \%$ supplementary cementing materials (SCMs). The CEM II/B type is not used in Lithuania.

The mitigating effect of the SCMs, particularly fly ash and slag, is well known and has been extensively studied [16-20]. Due to the pozzolanic reaction, SCMs reduce the alkalinity of the pore solution by consuming $\mathrm{OH}^{-}$and binding the alkali, consuming portlandite and reducing the permeability of the concrete $[5,16$, 19, 21-23]. According to the ASR model proposed by [18], a sufficient amount of fine siliceous admixtures in concrete prevent the formation of a tight reaction rim of calcium alkali silicate around the aggregate particles by absorbing all $\mathrm{Ca}^{2+}$ ions. A comprehensive review of the result for the effect of the SCMs on ASR was made by M. Thomas [16]. It is concluded that SCMs are an effective means for controlling the expansion due to the ASR and the necessary level of SCM replacement increases with the increasing available alkali from the Portland cement and the other concrete components, the $\mathrm{CaO} / \mathrm{SiO}_{2}$ ratio of the $\mathrm{SCM}$ and the reactivity of the aggregates. The fineness of the SCMs is also an important property affecting the pozzolanic activity [21, 24, 28]. S. Chatterjis stated [2] that a small addition of pozzolan of improper grading and the reactivity to a concrete structure may increase expansion. With respect to FA with a higher $\mathrm{CaO}$ and alkali content, the low replacement activates the ASR and the "pessimum effect" is present, i.e., the expansion becomes lower instead $[1,22]$. For FA with $10 \% \mathrm{CaO}$ (the limit value for FA when used for CEM II cement) the pessimum effect often occurs for the replacements around $15 \%$ [25]. Obviously, the effect of the SCMs of CEM II will not necessarily be positive in terms of the ASR.

This paper investigates the effectiveness of the SCMs (granulated blast furnace slag, fly ash, burnt shale) contained in the Portland-composite cement CEM
II/A (EN 197-1) on mitigating the ASR in cementitious structures with Lithuanian gravel aggregates. The investigations are based on the RILEM Recommended Test Methods and the ASTM C 1567 provisions.

\section{EXPERIMENTAL}

Raw materials

Aggregates. Tests were done using aggregates from three Lithuanian gravel quarries (sand 0/4) according EN 13139. Basing on long-term experience in field conditions they can be relatively classified into three reactivity levels: most alkali-reactive from Jurbarkas quarry (code J); moderately alkali-reactive from Kvesai quarry (code K); least alkali-reactive from Rizgonys quarry (code R). The amount of reactive silica minerals in these aggregates was: $\mathrm{J}-4.38 \%$; $\mathrm{K}-4.11 \%$; $\mathrm{R}-3.85 \%$.

Cementitious binders. Factory made Portland cement CEM I and Portland-composite cements CEM II/A (slag and burnt shale) and blended Portland-fly ash cements were used for the tests (Table 1). Chemical, physical and mechanical properties of cementitious materials used are given in Table 2.

\section{Methods of testing}

The RILEM recommended AAR-2 test method (option AAR-2.2, "short thick" EN specimens, $40 \times 40 \times$ $\times 160 \mathrm{~mm}$ ) was used to assess the ASR potential of the aggregates [26]. According to this method, the mortar specimens, (the aggregate/cementitious binder ratio was 2.25, the water/cementitious binder ratio was 0.47 ), hardened under special conditions (1 day in forms at $20{ }^{\circ} \mathrm{C}$ in a moisture cabinet and 1 day in water at $80{ }^{\circ} \mathrm{C}$ ), were stored for 28 days in a $1 \mathrm{M} \mathrm{NaOH}$ solution at $80{ }^{\circ} \mathrm{C}$ and their expansion was regularly measured. The modified ASTM C 1567 [27] method was used to evaluate the effect of the SCMs present in the Portland composite cements CEM II/A, i.e., "short thick" EN specimens were used instead of "long thin" ASTM

Table 1. The cementitious binders and codes.

\begin{tabular}{lcc}
\hline Cementitious binder & $\begin{array}{c}\text { SCMs content } \\
(\%)\end{array}$ & Codes \\
\hline $\begin{array}{l}\text { Portland cement } \\
\text { CEM I 52,5 R }\end{array}$ & - & PC \\
\hline $\begin{array}{l}\text { Portland-slag cement } \\
\text { CEM II/A-S 42,5 N }\end{array}$ & $\sim 15$ & PCS15 \\
\hline $\begin{array}{l}\text { Portland-burnt shale cement } \\
\text { CEM II/A-T 52,5 R }\end{array}$ & $\sim 18$ & PCT18 \\
\hline $\begin{array}{l}\text { Blended Portland-fly ash } \\
\text { cement (CEM I + FA) }\end{array}$ & 10 & PCFA10 \\
\hline
\end{tabular}


specimens. The ASTM 1567 and AAR-2 methods, as well as the ASTM 1260 method (also called AMBT methods) are identical; the only difference is that the EN specimens can be used in the AAR-2 test method. The ASR potential of the aggregates and their combinations with different cementitious materials is determined based on the changes in length, i.e., the expansion of the specimens. The critical expansion value below which the aggregates are considered to be very unlikely to be alkali-reactive or their combinations are likely to produce the acceptable expansion for the "long thin" specimens is $0.1 \%$ after storage for 14 days in the alkali solution. For slow reactive aggregates, this value should be lower $(0.08 \%)$ or the time of the storage in alkali solution should be longer ( 21 or 28 days) [9, 15, 22]. The $0.08 \%$ value is also given in $[24,28]$, when the efficiency of FA in mitigating the ASR is evaluated. The critical expansion values for the "short thick" specimens have not been finally agreed. The expansion of such specimens is slower compared to the "long thin" specimens and lower expansion values are recorded for a certain time. A number of tests were performed in order to find the ratio of the EN specimen to the ASTM specimen expansion value, however, the obtained values of this ratio vary across a very wide range, primarily due to the variety of the aggregates. In [29], the ratio of 0.6 is given for values after 14 days of storage, the ratio of 0.54 is given in the previous version of AAR-2 (A-TC 106-2) [30]. Based on the findings of the EU PARTNER research programme [7], the ratio in the region from 0.75 to 0.80 was suggested, although the spread of values obtained according to the testing programme has been very large. The same range is specified in the RILEM AAR-0 document [15]. A prolonged time in storage is also proposed (21 or 28 days [22, 28] or even 90 days [31]). The critical expansion value interval between $0.075 \%$ and $0.08 \%$ after 21 days of storage was chosen in our tests to assess the potential ASR. The length comparator E077 (MATEST) with the digital indicator ID-C112B (resolution of $0.001 \mathrm{~mm}$, measuring range of $12.7 \mathrm{~mm}$, accuracy of $0.003 \mathrm{~mm}$, measuring force of $0.9 \mathrm{~N}$ ) was used to measure the change in the length of the mortar specimens.

The changes in the strength of the specimens stored in the alkali solution for 28 days were also measured. The flexural and compressive strengths of the specimens were determined according to the requirements of standard EN 196-1. The tests were conducted in the powerful testing machine $\mathrm{H} 200 \mathrm{KU}$ with a capacity of $200 \mathrm{kN}$ and load measurement accuracy $\pm 0.5 \%$.

In order to assess the mitigating effect of the SCMs on the surface deterioration (the prevailing damage of the concrete structures with the Lithuanian aggregates), mortar specimens made according to the AAR-2 requirements and hardened for one day in forms at $20{ }^{\circ} \mathrm{C}$ were stored in the ASR intensifying warm and humid environment at $60{ }^{\circ} \mathrm{C}$ and $100 \% \mathrm{RH}$ (the conditions specified in AAR-4.1 [32]). Alkali-reactive aggregates $\mathrm{J}$ were used in the tests. The specimens were regularly checked for damage and their expansion was also measured. Specimens with plain Portland Cement CEM I were used as reference specimens.

The changes in the hardening structure were investigated by the ultrasonic pulse velocity (UPV) measurement method using a Pundit 7 device (a range from 0.1 to $6553 \mu \mathrm{s}$, a resolution of $0.1 \mu \mathrm{s}$, the frequency

Table 2. The chemical, physical and mechanical properties of the cementitious materials.

\begin{tabular}{|c|c|c|c|c|c|c|c|c|}
\hline \multirow[b]{2}{*}{ Item } & \multicolumn{2}{|c|}{$\mathrm{PC}$} & \multicolumn{2}{|c|}{ PCS15 } & \multicolumn{2}{|c|}{ PCT18 } & \multicolumn{2}{|c|}{ FA } \\
\hline & Value & $\begin{array}{l}\text { Standard } \\
\text { deviation }\end{array}$ & Value & $\begin{array}{l}\text { Standard } \\
\text { deviation }\end{array}$ & Value & $\begin{array}{l}\text { Standard } \\
\text { deviation }\end{array}$ & Value & $\begin{array}{l}\text { Standard } \\
\text { deviation }\end{array}$ \\
\hline \multicolumn{9}{|c|}{ Chemical composition $(\%)$} \\
\hline$\overline{\mathrm{SiO}_{2}(\%)}$ & 19.04 & \pm 0.07 & 21.69 & \pm 0.06 & 21.96 & \pm 0.07 & 50.05 & \pm 0.08 \\
\hline $\mathrm{CaO}(\%)$ & 62.29 & \pm 0.11 & 60.48 & \pm 0.12 & 56.82 & \pm 0.14 & 3.51 & \pm 0.12 \\
\hline $\mathrm{Al}_{2} \mathrm{O}_{3}(\%)$ & 4.89 & $\pm 0,09$ & 5.01 & \pm 0.08 & 6.33 & \pm 0.08 & 26.86 & \pm 0.10 \\
\hline $\mathrm{Fe}_{2} \mathrm{O}_{3}(\%)$ & 3.25 & \pm 0.06 & 2.88 & \pm 0.07 & 3.50 & \pm 0.08 & 4.74 & \pm 0.05 \\
\hline $\mathrm{MgO}(\%)$ & 3.29 & \pm 0.10 & 3.20 & \pm 0.12 & 3.78 & \pm 0.11 & - & - \\
\hline $\mathrm{Na}_{2} \mathrm{O}(\%)$ & 0.10 & \pm 0.01 & 0.14 & \pm 0.01 & 0.11 & \pm 0.01 & 0.62 & \pm 0.01 \\
\hline $\mathrm{K}_{2} \mathrm{O}(\%)$ & 1.07 & \pm 0.01 & 1.00 & \pm 0.01 & 2.05 & \pm 0.01 & 2.98 & \pm 0.01 \\
\hline $\mathrm{Na}_{2} \mathrm{O}_{\text {ekv }}(\%)$ & 0.80 & \pm 0.02 & 0.80 & \pm 0.02 & 1.46 & \pm 0.02 & 2.58 & \pm 0.02 \\
\hline $\mathrm{SO}_{3}(\%)$ & 3.45 & \pm 0.05 & 2.97 & \pm 0.04 & 3.49 & \pm 0.06 & 0.28 & \pm 0.04 \\
\hline $\mathrm{CaO}_{\text {free }}(\%)$ & 0.50 & \pm 0.06 & 0.47 & \pm 0.05 & 1.21 & \pm 0.07 & 0.08 & \pm 0.05 \\
\hline L.O.I $(\%)$ & 1.81 & \pm 0.03 & 1.19 & \pm 0.03 & 1.60 & \pm 0.04 & 4.82 & \pm 0.04 \\
\hline Insoluble residue $(\%)$ & 0.34 & \pm 0.04 & 0.55 & \pm 0.04 & 2.91 & \pm 0.04 & - & \pm 0.04 \\
\hline \multicolumn{9}{|c|}{ The mechanical and physical properties } \\
\hline Early strength (MPa) & 39.1 & \pm 0.5 & 23.3 & \pm 0.6 & 31.5 & \pm 0.5 & - & - \\
\hline Standard strength (MPa) & 64.9 & \pm 1.0 & 53.3 & \pm 0.9 & 63.9 & \pm 0.9 & - & - \\
\hline Initial setting time (min) & 125 & \pm 10 & 135 & \pm 12 & 290 & \pm 14 & - & - \\
\hline Fineness (Blaine), $\left(\mathrm{m}^{2} \mathrm{~kg}^{-1}\right)$ & 529 & \pm 4 & 531 & \pm 5 & 434 & \pm 4 & 315 & \pm 3 \\
\hline Soundness (mm) & 0 & - & 0 & - & 2.0 & - & - & - \\
\hline
\end{tabular}


of the transducers of $54 \mathrm{kHz}$ ). The measuring surface of the standard cylindrical heads was pressed against the specimen at two strictly opposite points. Vaseline was used to ensure good contact. The UPV was calculated from the following equation:

$$
V=\frac{l}{\tau} \cdot 10^{6}
$$

where $l$ is the length of the tested mortar specimen (the distance between the cylindrical heads) in $\mathrm{m}, \tau$ is the time of pulse the spread in $\mu$ s.

\section{Codes of the specimens}

The codes (designation) of the tested mortar specimens consist of the aggregate code ( $\mathrm{J}, \mathrm{K}$ or R, see 2.1) and the code of the cementitious binder (Table 2).

\section{RESULTS}

\section{Storage in the $1 \mathrm{M} \mathrm{NaOH}$ \\ solution at $80^{\circ} \mathrm{C}$}

\section{Expansion}

Figure 1 shows the progression of the expansion of the specimens during the 28 days when it was tested according to the AAR-2 test methodology. The results show that, after 21 days in storage, the expansion of all the specimens exceeds the critical values specified in the different sources $[13,15,29]$. The biggest expansion was observed in the specimens with aggregate J, whereas the specimens with aggregate $\mathrm{R}$ had the smallest expansion. The test results coincide with the known reactivity of these aggregates in the field.

Figures 2, 3 and 4 illustrate the expansion of specimens with the aggregates and different binders in the alkali solutions. The slags and fly ash present in the Portland cement evidently reduce the expansion of the specimens. After 21 days in storage, the expansion of the specimens with the Portland slag cement (JPCS15

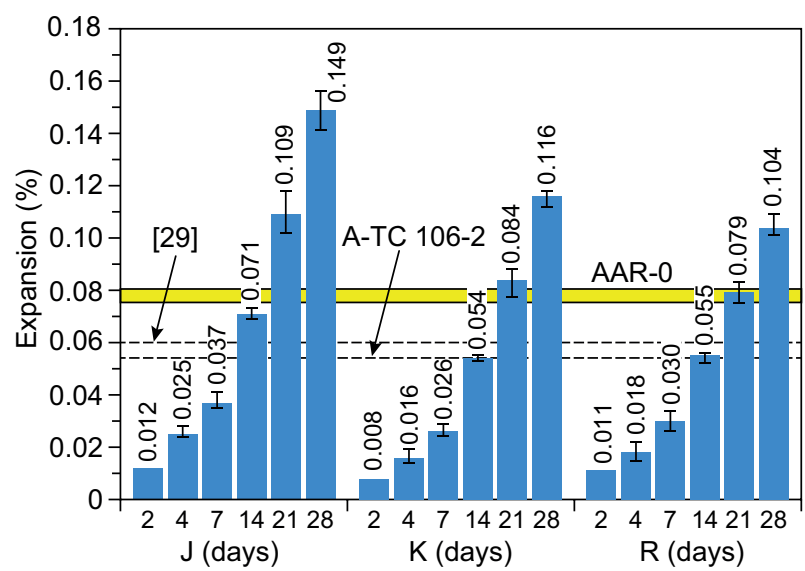

Figure 1. The expansion of the mortar specimens with the different aggregates. and KPCS15) is already within the interval of the critical values $(0.075-0.08 \%)$, the expansion values of the RPCS15 specimens are below the interval values. When the Portland cement contains $10 \%$ or $15 \%$ FA, the expansion decreases similarly to the PCS15 specimens. The expansion of the specimens made of a Portland cement containing $20 \%$ FA drops significantly and the values $(0.050-0.055 \%)$ after 21 days are much lower than the critical expansion values. The opposite effect is observed when a Portland-burnt shale cement is used: the expansion of the PCT18 specimens is higher when compared to the expansion of the specimens with the plain Portland cement CEM I. It is not excluded that the expansion of PCT18 itself may have a certain effect (see Table 1).

\section{Strength and UPV}

The changes of these indicators in the specimens with the reactive aggregates depend on two opposite factors: on the one hand, ASR causes destructive processes, on the other hand, hardening of the cementitious binder makes the structure denser and stronger. Therefore, the strength and UPV changes reflect the cumulative effect of these opposite factors; in other words, the changes in strength and UPV illustrate a compromise between the hardening of the structure and its destruction. The obtained results are presented in Table 3. The change in the compressive strength $\left(R_{c}\right)$ is not an informative indicator for determining the potential ASR in various combinations of the cementitious binder and the aggregates. The gain of this strength is observed in all the combinations and it is not actually related to the aggregate reactivity level and only in two cases is it related to the composition of the cementitious materials: in combination with PCS15, a higher gain of strength (alkaline activation of slag), in combination with CT18, a noticeably lower gain in strength is observed. The flexural strength $\left(\mathrm{R}_{\mathrm{f}}\right)$ is much more sensitive both to the binders and the aggregates used. In some combinations, with much reactive aggregate $(\mathrm{J})$, the loss in flexural strength is observed (JPC, JPCT18) or it remains stable (JPCFA10, JPCFA15) and, only in the JPCS15 and JPCFA20 combinations, the flexural strength increases, demonstrating a gain similar to that of the compressive strength. Similar trends in the change in the flexural strength are observed in combinations with less reactive aggregates $(K, R)$ and the values of these changes reveal a weaker deleterious effect of the ASR in them. The loss in the flexural strength is observed only in combinations with Portland burnt-shale cement (KPCT18, RPCT18) and this loss is smaller than in the combinations with J aggregates. A gain in the flexural strength $(9 \%)$ is observed in the combinations with plain Portland cement (KPC, RPC), although this gain is much smaller when compared to the combinations with the SCMs: KPCS15 (52\%), RPCS15 (41\%) and KPCFA20 (35\%), RPCFA20 (28\%). 


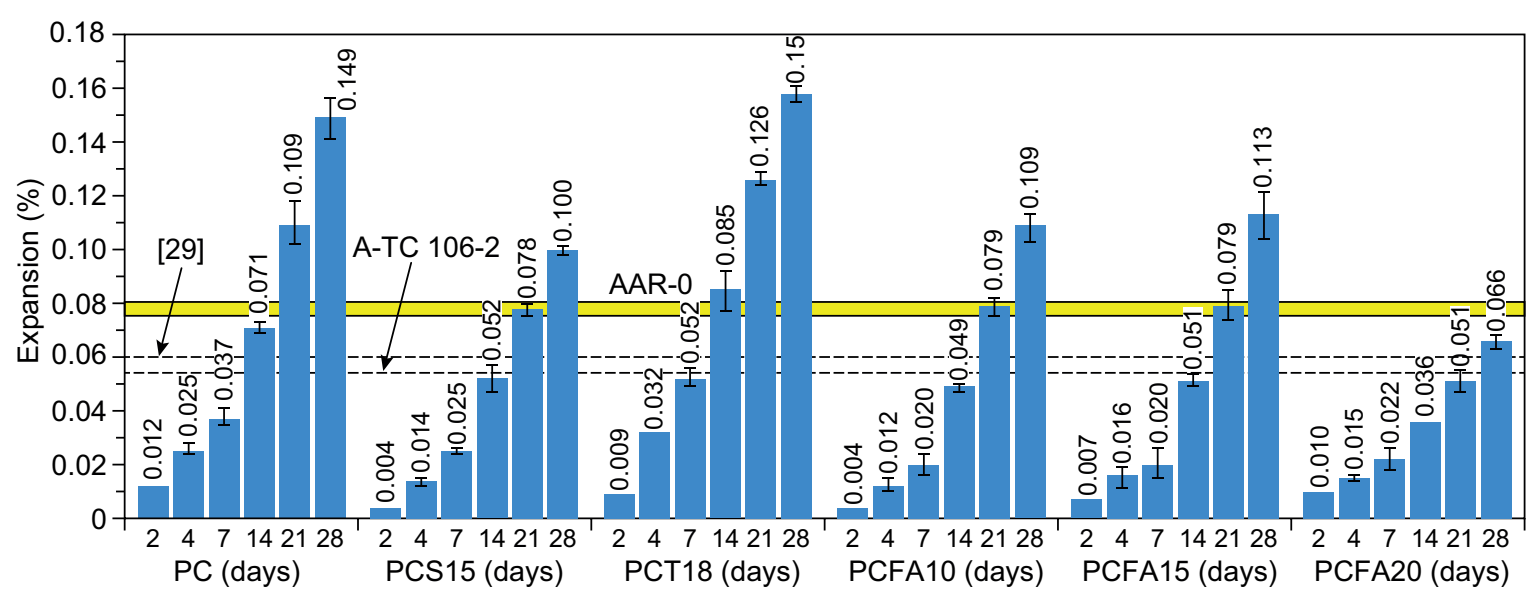

Figure 2. The expansion of the mortar specimens with the $\mathrm{J}$ aggregate.

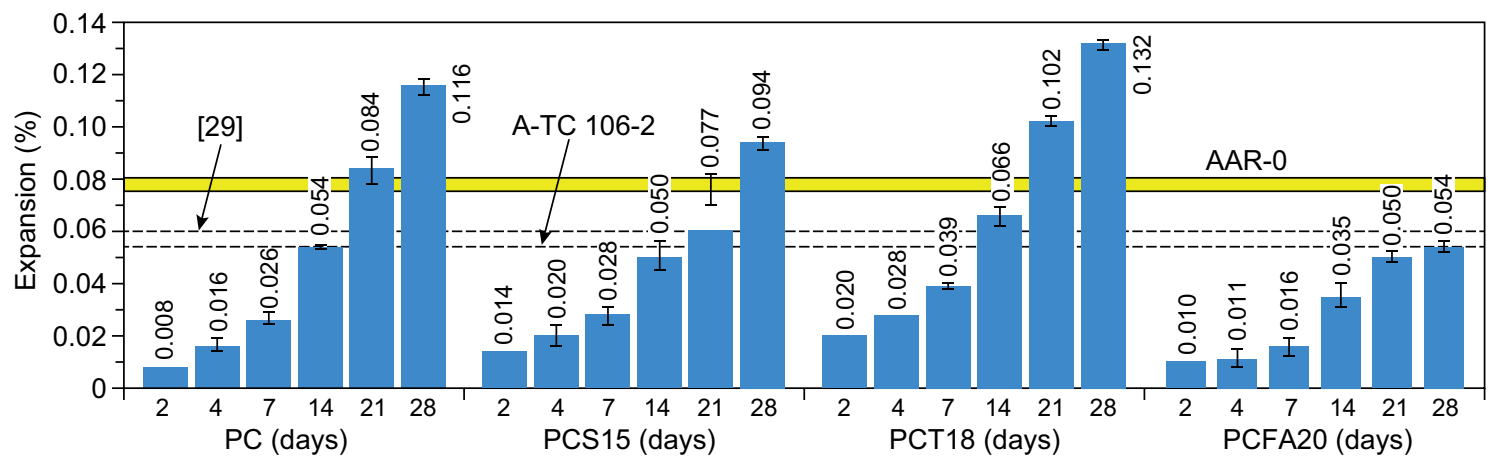

Figure 3. The expansion of the mortar specimens with the $\mathrm{K}$ aggregate.

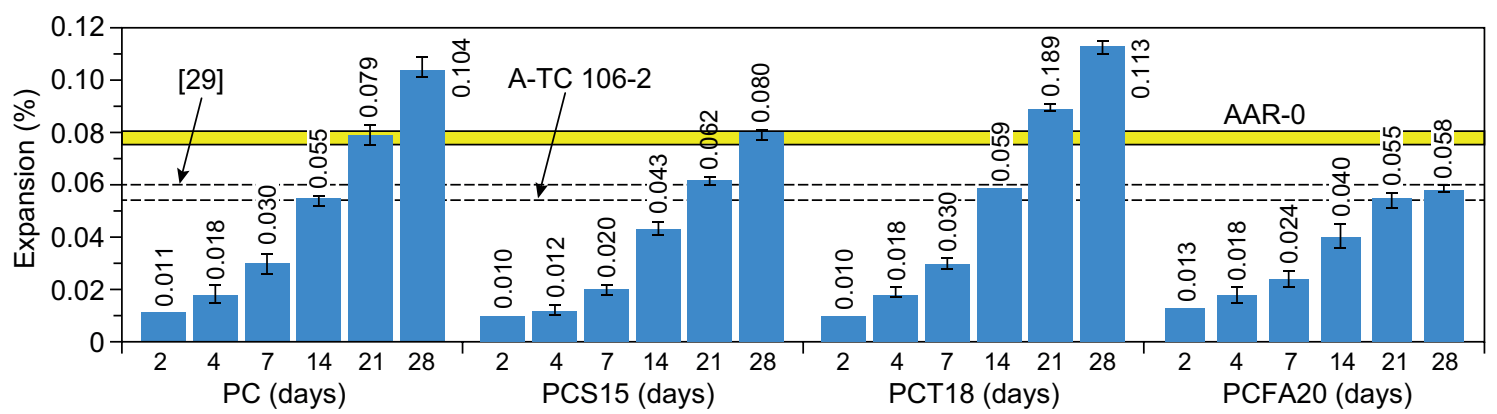

Figure 4. The expansion of the mortar specimens with the R aggregate.

Table 3. The changes in the strength and UPV of the specimens after 28 days in storage in a $1 \mathrm{M} \mathrm{NaOH}$ solution at $80^{\circ} \mathrm{C}$.

\begin{tabular}{|c|c|c|c|c|c|c|c|c|c|}
\hline \multirow{3}{*}{ Binder } & \multicolumn{6}{|c|}{ The change in strength and UPV (\%) } & & & \\
\hline & \multicolumn{3}{|c|}{ Aggregate J } & \multicolumn{3}{|c|}{ Aggregate K } & \multicolumn{3}{|c|}{ Aggregate $\mathrm{R}$} \\
\hline & $R_{\mathrm{f}}$ & $R_{\mathrm{c}}$ & UPV & $R_{\mathrm{f}}$ & $R_{\mathrm{c}}$ & UPV & $R_{\mathrm{f}}$ & $R_{\mathrm{c}}$ & $\overline{\mathrm{UPV}}$ \\
\hline$\overline{\mathrm{PC}}$ & -9 & +25 & -3 & +9 & +32 & -1 & +9 & +30 & $\overline{+3}$ \\
\hline PCS 15 & +45 & +48 & +11 & +52 & +51 & +14 & +41 & +72 & +9 \\
\hline PCFA 10 & 0 & +35 & +2 & - & - & - & - & - & - \\
\hline PCFA15 & +2 & +28 & +1 & - & - & - & - & - & - \\
\hline PCFA20 & +30 & +37 & +3 & +35 & +30 & +6 & +28 & +23 & +7 \\
\hline PCT18 & -17 & +14 & -1 & -1 & +19 & +3 & -8 & +24 & +3 \\
\hline
\end{tabular}


Figure 5 illustrates the relationship between the 28-day flexural strength and the expansion (the values of the specimens with PCS15 are excluded due to its specific hardening in the alkali solution). There is a linear correlation between the expansion and flexural strength $(\mathrm{R}=0.95)$. The statistical regression analysis produced a regression equation, which describes the relationship between the changes in the flexural strength and the expansion (within the range of the obtained experimental test results under the same experimental conditions, standard deviation $\mathrm{s}_{\mathrm{x}}=5.66 \%$ ).

The changes in the UPV is similar to the changes in the flexural strength: the least or even a negative UPV gain is observed in the specimens containing the most reactive aggregate $J$ (except for JPCS15). In the case of the different binders, the UPV gain is either observed in the specimens with PCS15 ( 9 - $14 \%$ ), followed by the specimens with CFA20 (3 - 7 \%). A lower FA content in the binder (specimens JPCFA10 and JPCFA15) reduces the UPV gain ( $1 \%$ and $2 \%$ respectively). The least or even a negative UPV gain in the specimens with the same aggregate are observed when the PC and PCT18 binders are used.

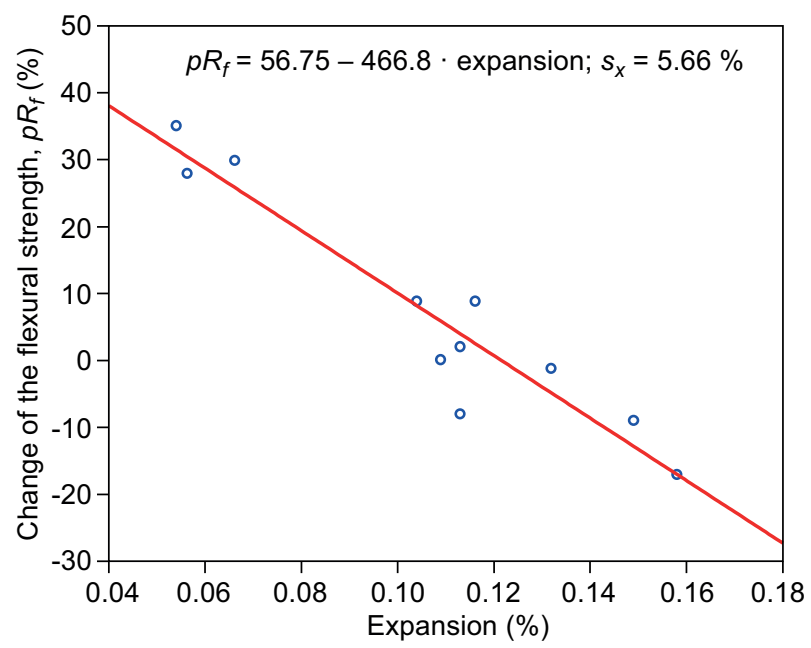

Figure 5. The relationships between the 28-day changes in the flexural strength and the expansion of the specimens in the AAR-2.2 test.

\section{Storage in the environment of} $100 \% \mathrm{RH}$ at $60{ }^{\circ} \mathrm{C}$

\section{Surface damage}

The majority of the ASR-caused damages visible to the naked eye (pop-outs, silica gel stains, crackings) on the specimens stored in the warm humid environment occurred during the first five weeks. During the next 10 weeks they became more evident and expanded, new spots of ASR damage were few. Later on (the entire storage time was 25 weeks), the appearance of the specimens was almost unchanged. The intensity of the damage on the surface of the specimens with the different aggregates corresponded to the aggregates reactivity when tested according AAR-2 (Figure 1): the specimens with the most reactive $\mathrm{J}$ aggregate were the most defected, whereas the specimens with $\mathrm{R}$ aggregate were the least defected. The amount and intensity of the surface deterioration in the specimens with the SCMs and the specimens with the plain Portland cement were compared to assess the effectiveness of the SCMs for mitigating the ASR. The generalised results of the visual inspection are presented in Table 4. Figure 6 illustrates the images of the specimens with the most reactive $\mathrm{J}$ aggregate.

It can be seen that the SCMs present in the Portland composite cement have a different effect on the ASR-caused surface damage. $15 \%$ of the slag in the Portland composite cement actually has no mitigating effect for ASR; burnt shale causes more intensive surface damage; for fly ash a "pessimum" effect is observed, i.e., an insufficient amount of FA content in the Portland composite cement (10\% and $15 \%$ ) intensifies the damage and the mitigating effect is observed only with an FA content of $20 \%$. The comparison these results and the results of the tests in the hot alkaline solution (see section "Storage in the $1 \mathrm{M} \mathrm{NaOH}$ solution at $\left.80^{\circ} \mathrm{C}^{\prime \prime}\right)$ shows that the assessment of the SCMs effect on the ASR is only the same in the cases of PCT18 (stimulating effect) and PCFA20 (mitigating effect).

Table 4. The results of the visual monitoring of the specimens with the different binders, stored at $60{ }^{\circ} \mathrm{C}$ and a $100 \% \mathrm{RH}$ environment for 15 weeks.

\begin{tabular}{ll}
\hline Binder & Damage intensity \\
\hline PC & $\begin{array}{l}\text { The biggest amount of damage (cracks, big } \\
\text { silica gel stains, pop-out) was observed on the } \\
\text { specimens with aggregate J. There is much less } \\
\text { damage on the specimens with the K and R } \\
\text { aggregates, small gel stains are prevailing. }\end{array}$ \\
\hline PCS15 & $\begin{array}{l}\text { The appearance of the specimens with any } \\
\text { aggregate is similar to that of the specimens with } \\
\text { the plain PC. }\end{array}$ \\
\hline PCFA10 & $\begin{array}{l}\text { The specimens have much more damage and they } \\
\text { are more intensively compared to the specimens } \\
\text { with the plain PC. }\end{array}$ \\
\hline PCFA15 & $\begin{array}{l}\text { The specimens have much more damage than } \\
\text { the specimens with the plain PC, however, there } \\
\text { is less damage when compared to the CFA10 } \\
\text { specimens. }\end{array}$ \\
\hline PCFA20 & $\begin{array}{l}\text { The specimens have much less damage than the } \\
\text { specimens with the plain PC (aggregate J) or no } \\
\text { damages at all (aggregate R and some specimens } \\
\text { with aggregate K); besides, the existing damage is } \\
\text { small (insignificant). }\end{array}$ \\
\hline PCT18 & $\begin{array}{l}\text { The specimens have much more damage and they } \\
\text { are more intensively compared to the specimens } \\
\text { with the plain PC. }\end{array}$ \\
\hline &
\end{tabular}


In the case of PCS15, the specimens expand less, but the intensity of the surface damage is almost the same as in the specimens with the plain PC, whereas binders PCFA10 and PCFA15 even produce the opposite results: the expansion is lower, but the ASR-caused surface damage is much more intensive compared to the specimens without FA.

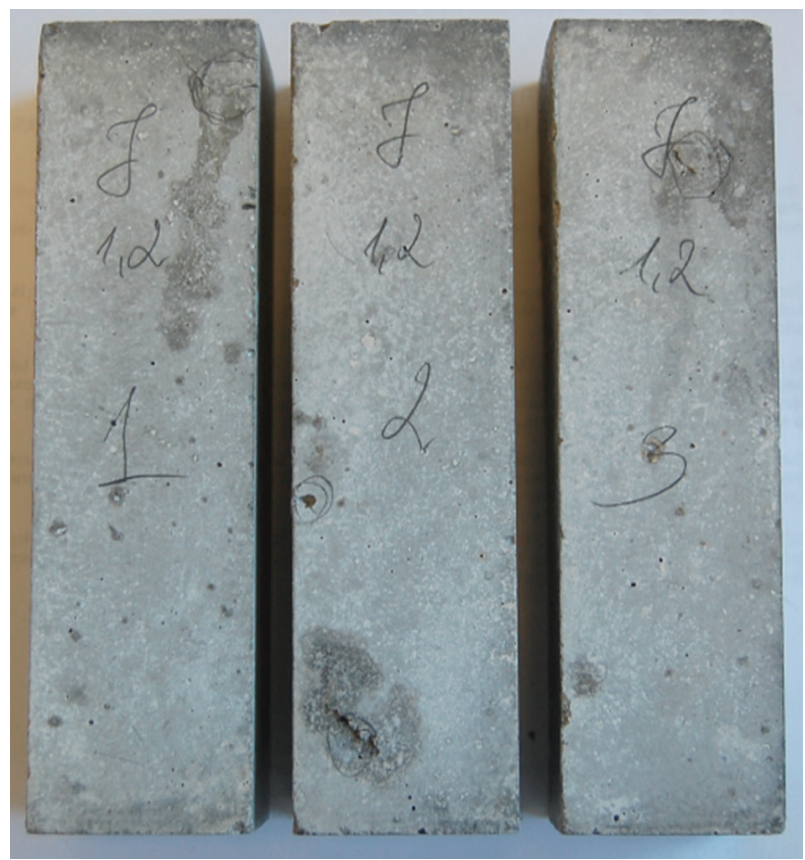

a)

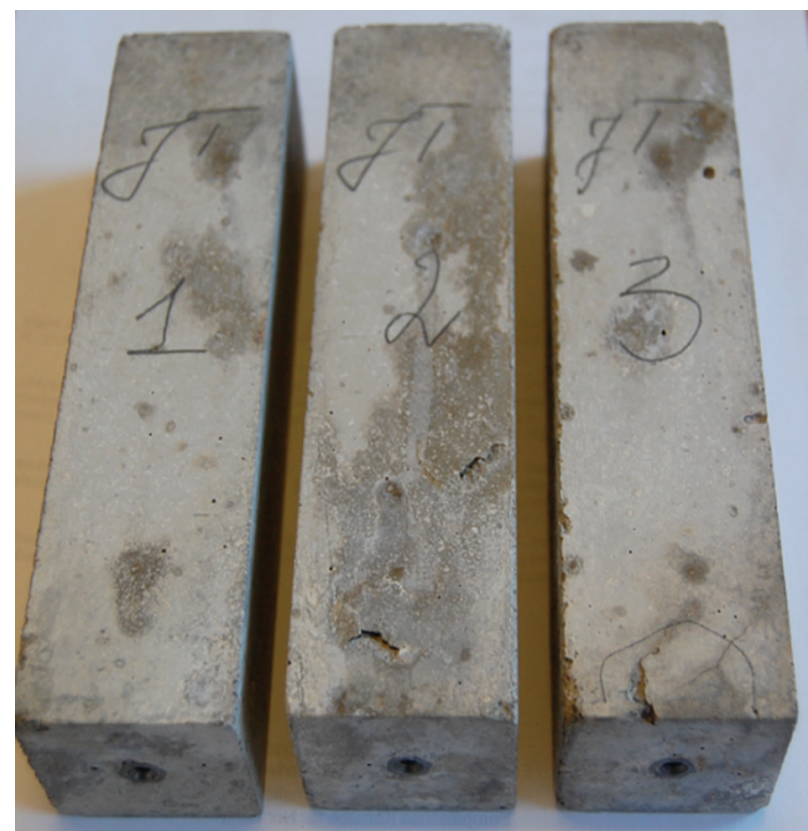

c)

\section{Expansion}

The specimens of almost all the compositions demonstrated little (not exceeding $0.015 \%$ after 25 weeks) or no expansion in the warm and humid environment. Only the specimens with PCT18 expanded more: after 15 weeks, the expansion of the specimens with $\mathrm{J}, \mathrm{K}$ and $\mathrm{R}$ aggregates was $0.034 \%, 0.027 \%$ and $0.016 \%$ and after 25 weeks the expansion was $0.055 \%, 0.048 \%$ and $0.034 \%$, respectively.

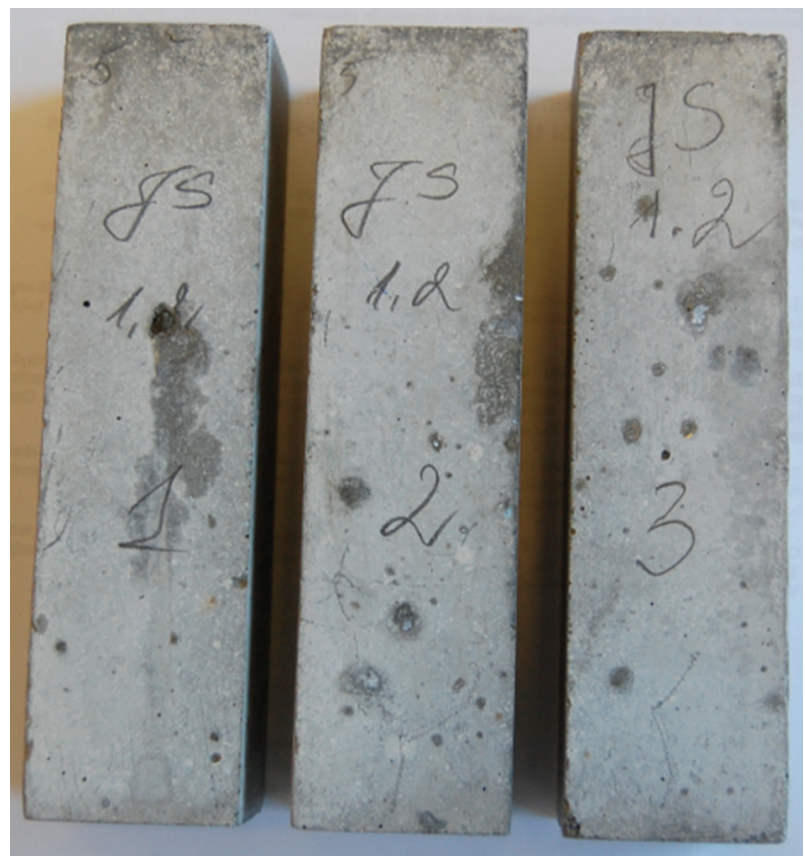

b)

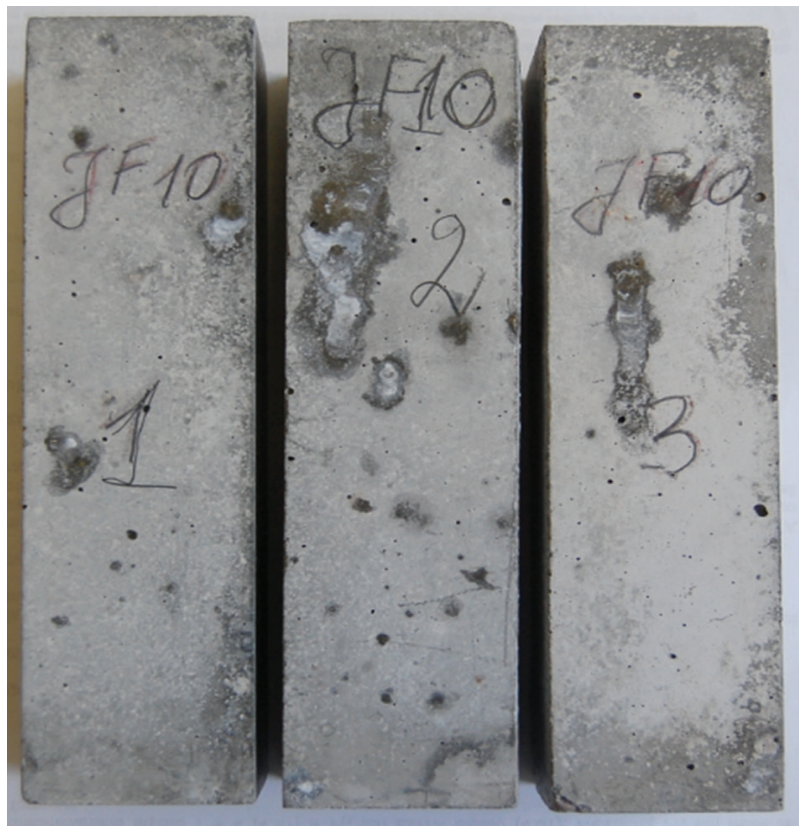

d)

Figure 6. The appearance of the specimens with J aggregate stored at $60{ }^{\circ} \mathrm{C}$ and in a $100 \% \mathrm{RH}$ environment for 15 weeks: a) JPC; b) JPCS15; c) JPCT18; d) JPCFA10; e) JPCFA15; f) JPCFA20. (Continue on next page) 


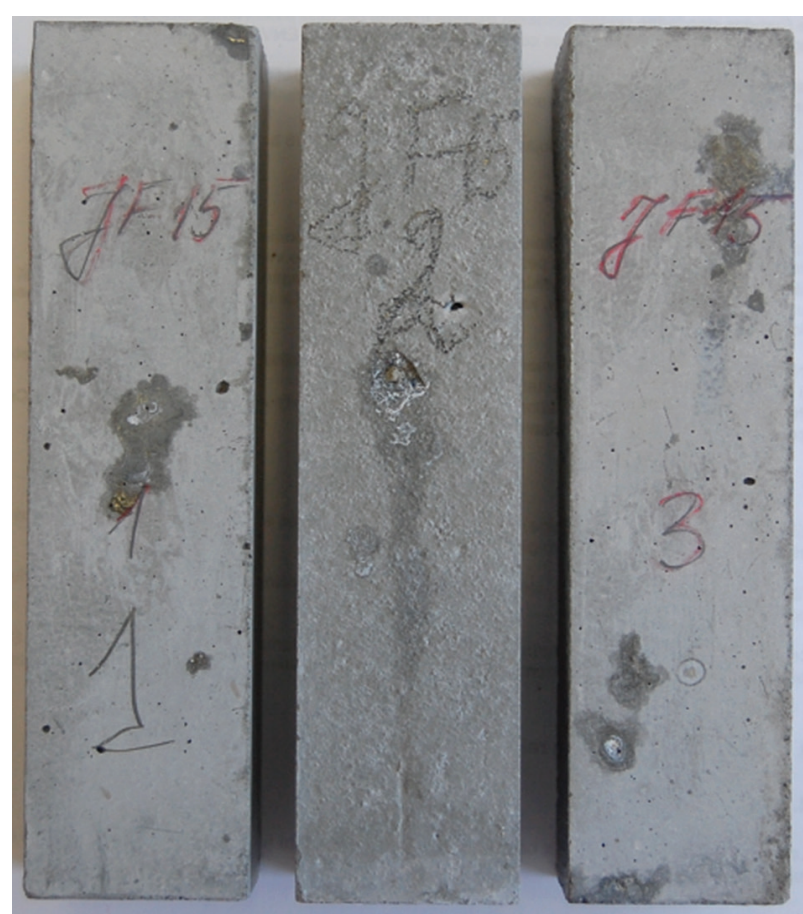

e)

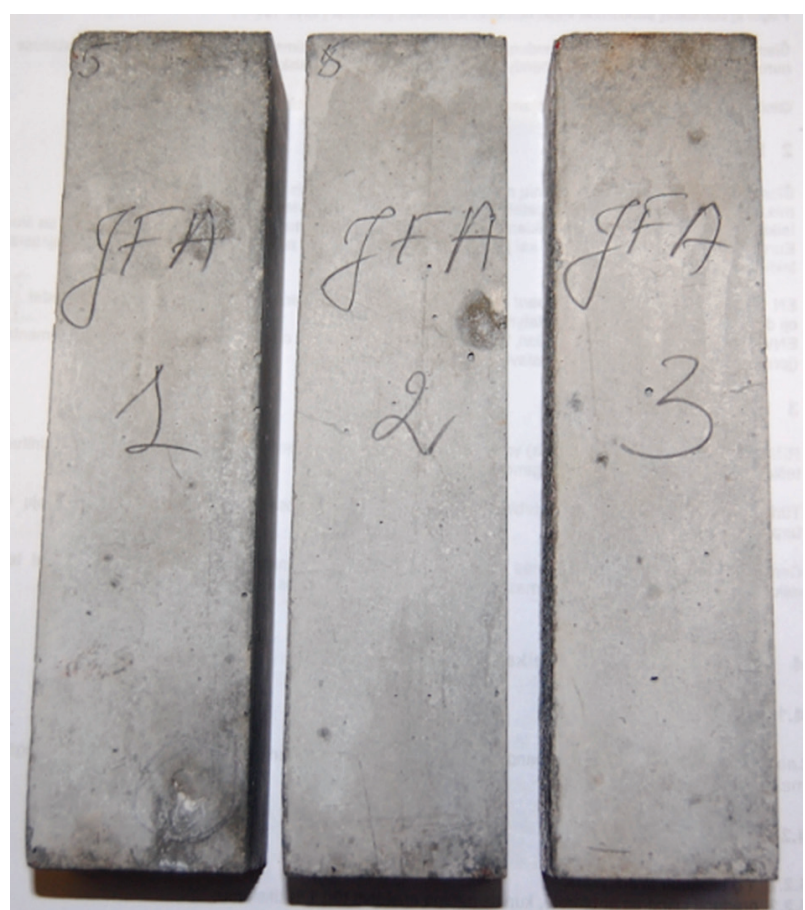

f)

Figure 6. The appearance of the specimens with $\mathrm{J}$ aggregate stored at $60{ }^{\circ} \mathrm{C}$ and in a $100 \% \mathrm{RH}$ environment for 15 weeks: a) JPC; b) JPCS15; c) JPCT18; d) JPCFA10; e) JPCFA15; f) JPCFA20.

\section{DISCUSSION}

The field performance of the investigated aggregates shows that the $\mathrm{J}$ aggregate is the most reactive, followed by the less reactive $\mathrm{K}$ aggregate and the least reactive $\mathrm{R}$ aggregate. The results of the accelerated mortar-bar test (the AAR-2.2 method) are in agreement with field experience: the specimens with the J aggregate demonstrated the biggest expansion and specimens with the $\mathrm{R}$ aggregate expanded the least (Figure 1). The good agreement of the results in the accelerated mortarbar test and known reactivity of the aggregates in the field is also presented in [7,33]. The SCMs present in the Portland composite cement CEM II have a different effect on the expansion: the slag and fly ash reduce the expansion; the burnt shale increases the expansion. The changes in the flexural strength and UPV of the specimens stored in the $1 \mathrm{M} \mathrm{NaOH}$ solution for 28 days also show a similar SCM effect on the ASR. A loss in strength was observed in the specimens with the PCT18 binder, the changes in the UPV values are also negative or slightly positive. Whereas the changes in the mentioned values were always positive in specimens with the PCS15 and PCFA binders, i.e., the ASR-caused damage of the hardening structure in these compositions is weaker when compared to its development or there is no damage at all. A higher gain in flexural strength and the UPV in the compositions with CS15 does not mean more effective ASR mitigation by the slag because it is partly caused by the specific hardening of the slag Portland cement (lower early-age strength of the specimens prior to soaking into the alkaline solution due to the slower hardening process) and the further activation of the slag component by the alkali. The negative effect of the burnt shale (big expansion, loss in flexural strength and the UPV in the alkaline solution) is probably caused by the high $\mathrm{CaO}_{\text {free }}$ content in the shale $[34,35]$. A statistical analysis of the results shows a strong linear correlation $(\mathrm{R}=0.95)$ between the expansion values and the changes in the 28-day flexural strength in the AMBT test. While the changes in 28-day compressive strength do not indicate the potential ASR. A number of scientists also state that the compressive strength, particularly at early ages, is not a good indicator for the evaluation of the ASR potential [3,36-38]. According to Islam and Ghafoori [3], the storage time in the alkaline solution should be at least 26 weeks and the change in compressive strength between 4 and 26 weeks should be measured.

Monitoring the damages on the surface of the specimens stored at $60{ }^{\circ} \mathrm{C}$ in a $100 \% \mathrm{RH}$ environment (in accordance with RILEM AAR-4.1) [32] showed that the results are not always in agreement with the AMBT test results. Only the potential ASR of the different aggregates was equally assessed by both methods: the most significant ASR-caused surface damage and the biggest expansion was observed in the specimens with the $\mathrm{J}$ aggregate, whereas the specimens with the $\mathrm{R}$ aggregate expanded and were damaged the least. Meanwhile, the potential ASR of the combinations with 
the different cementitious binders can be different or even the opposite according to the results obtained by using the said test methods. In our tests, the results of the assessment of the expansion and surface damages (the intensity of the surface deterioration) only coincided in the cases of the PCT18 and PCFA20 binders: the specimens with the PCT18 binder experienced bigger expansion and had much more damage, whereas the specimens with PCFA20 experienced little expansion and had less damage when compared to the specimens made of the plain PC (Table 4, Figures 2-4 and 6). Although the presence of slag in the cement (specimens with PCS15) diminished the expansion, it did not reduce the amount of damage. The lower FA content in the binder (10\% and $15 \%)$ diminished the expansion, but intensified the appearance of the ASR-caused damage, especially in cases where the binder contained $10 \%$ FA (Figure 6d). The intensity of the damage revealed the "pessimum" effect when the FA when used at too low replacement level, which does not mitigate, but even intensifies the ASR induced deterioration. However, no "pessimum" effect was observed in terms of expansion because it is known to pertain to high-lime FA only [24]. The results of these tests show that the assessment of the ASR mitigating effect of the SCMs present in the CEM II/A cement by expansion in the hot alkaline solution may be imprecise when combinations with aggregates like the Lithuanian gravel (containing impurities of reactive rocks) are tested. The $\mathrm{SCMs}$, such as slag or fly ash, present in the Portland-composite cement CEM II/A reduce the expansion, but fail to prevent or even intensify (in the case of FA) the occurrence of the ASRcaused damage (gel stains, pop-outs and cracks).

\section{CONCLUSIONS}

The following conclusions have been drawn from the experimental tests with the Lithuanian aggregates from gravel deposits, which usually contain $3-4 \%$ of reactive siliceous rocks, and their combinations with Portland-composite cements CEM II/A:

- The tested aggregate reactivity levels determined according to the different indicators (the expansion and changes in the flexural strength in the RILEM AAR-2.2 test, the volume of the surface damage due to ASR at $60{ }^{\circ} \mathrm{C}$ and $100 \% \mathrm{RH}$ ) are distributed in the same sequence and correspond to their known reactivity in the field. All tested aggregates could possibly be assigned to Class II-S.

- The SCMs present in the Portland-composite cement CEM II/A have a different effect on the ASR. Slag and low-lime FA components have a mitigating effect on the ASR in terms of expansion and change in the flexural strength in the accelerated mortar bar test, however, no mitigating effect for the ASR-caused surface damage (silica gel, pop-out, cracking) was observed when the specimens were stored in the warm humid environment. The FA component can even induce the ASR-caused surface damage, e.g., the "pessimum" effect is observed in the specimens containing $10 \%$ and $15 \%$ FA, where the damages are more numerous compared to the specimens made of the plain PC. Only the threshold content (20\%) of FA in the CEM II/A cement is effective, there are almost no damages in such specimens. The burnt shale component ( $18 \%)$ has a stimulating effect on the ASR: it increases specimen expansion, it reduces strength and intensifies the ASR-caused surface damage.

- A strong correlation (linear correlation, $\mathrm{R}=0.95$ ) between the change in the flexural strength and expansion was observed in the specimens that were made and conditioned under the conditions specified in AAR-2 and stored in the hot alkaline solution for 28 days: with the bigger the expansion, the strength gain is lower or even negative. A regression equation describing the relationship between the changes in the flexural strength and expansion was produced.

\section{REFERENCES}

1. Lindgård J., Andiç-Çakir Ö., Fernandes I., Rønning T.F., Thomas M.D.A. (2012): Alkali-silica reactions (ASR): Literature review on parameters influencing laboratory performance testing. Cement and Concrete Research, 42, 223-243.doi: 10.1016/j.cemconres.2011.10.004

2. Chatterji S. (2015): Chemistry of alkali-silica reaction and testing of aggregates. Cement and Concrete Composites, 27, 788-795. doi: 10.1016/j.cemconcomp.2005.03.005

3. Islam M.S., Ghafoori N. (2015): Relation of ASR-induced expansion and compressive strength of concrete. Materials and Structures, 48, 4055-4066. doi: 10.1617/s11527-0140465-6

4. McNally C., Richardson M.G. (2005): Reactivity assessment of aggregates: Role of chert crystallinity. ACI Materials Journal, 102 (3), 163-169.

5. Rajabipour F., Giannini E., Dunant C., Ideker J.H., Thomas M.D.A. (2015): Alkali-silica reaction: Current understanding of the reaction mechanisms and the knowledge gaps. Cement and Concrete Research, 76, 130-146. doi: 10.1016/j.cemconres.2015.05.024

6. Wigum B.J., Pedersen L.T., Grelk B., Lindgård J. (2006): State-of-the art report: Key parameters influencing the alkali aggregate reaction. EU "PARTNER" Project, Report 2.1. SINTEF Building and Infrastructure.

7. Lindgård J., Nixon P.J., Borchers I., Schouenborg B., Wigum B.J., Haugen M., Åkesson U. (2010): The EU „PARTNER“ Project - European standard tests to prevent alkali reactions in aggregates: Final results and recommendations. Cement and Concrete Research, 40, 611-635. doi: 10.1016/j.cemconres.2009.09.004

8. Sims I., Poole A.B. (2010). Alkali-Aggregate Reaction in Concrete: A Word Review. CRC Press, London, UK. 
9. Sims I., Nixon P.J., Marion A-M. (2004): International collaboration to control alkali-aggregate reaction: the successful progress of RILEM TC 106 and TC 191-ARP. in: Proceeding of the $12^{\text {th }}$ International Conference on Alkali-Aggregate Reaction in Concrete. pp.41-50.

10. Nixon P.J., Sims I. (2016). RILEM Recommendations for the Prevention of Damage by Alkali-Aggregate Reactions in New Concrete Structures. Springer.

11. CEN/TR 16349 (2012). Framework for the specification on the avoidance of a damaging Alkali-Silica Reaction (ASR) in concrete.

12. Gumuliauskas A., Navickas A., Štuopys A. (1996): Influence of structural state of $\mathrm{SiO}_{2}$ minerals on aggregate reactivity (in Lithuanian). Civil Engineering (Statyba), 3(7), 46-53. doi: 10.1080/13921525.1996.10531655

13. Žvironaitė J., Pranckevičienè J. (2017): The investigation of alkali-silica reactivity (ASR) of Lithuanian aggregates. Procedia Engineering, 172, 1305-1310. doi: 10.1016/j. proeng.2017.02.160

14. Gumuliauskas A., Vektaris B., Žvironaitè J. (2002): Alkaline Corrosion of Concrete in Lithuanian Conditions (in Lithuanian). Chemical Technology (Chemine technologija), 1(22), 33-39.

15. RILEM (2015). Recommended Test Method: AAR-0. Outline Guide to the Use of RILEM Methods in the Assessment of the Alkali-Reactivity Potential of Aggregates.

16. Thomas M. (2011): The effect of supplementary cementing materials on alkali-silica reaction: A review. Cement and Concrete Research, 41, 1224-1231. doi: 10.1016/j.cemconres.2010.11.003

17. Shehata M.H., Thomas M.D.A. (2010): The role of alkali content of Portland cement $\mathrm{n}$ the expansion of concrete prisms containing reactive aggregates and supplementary cementing materials. Cement and Concrete Research, 40 , 569-574. doi: 10.1016/j.cemconres.2009.08.009

18. Ichikawa T., Masazumi M. (2007): Modified model of alkali-silica reaction. Cement and Concrete Research, 37, 1291-1297. doi: 10.1016/j.cemconres.2007.06.008

19. Karakurt C., Topçu I.B. (2011): Effect of blended cements produced with natural zeolite and industrial by-products on alkali-silica reaction and sulphate resistance of concrete. Construction and Building Materials, 25, 1789-1795. doi: 10.1016/j.conbuildmat.2010.11.087

20. Duchesne J., Bérubé M-A. (2001): Long-term effectiveness of supplementary cementing materials against alkali-silica reaction. Cement and Concrete Research, 31, 1057-1063. doi: 10.1016/S0008-8846(01)00538-5

21. Venkatanarayanan H.K., Rangaraju P.R. (2013): Decoupling the effects of chemical composition and fineness of fly ash in mitigating alkali-silica reaction. Cement and Concrete Composites, 43, 54-68. doi: 10.1016/j.cemconcomp.2013.06.009

22. Hanna K.E., Morcous G. Tadros M.K. (2009): Effectiveness of Class C Fly Ash on Mitigating Alkali-Silica Reaction in Concrete Pavement. International Journal of Construction Education and Research, 5, 167-181. doi: 10.1080/15578770903152781

23. Shafaatian S.M.H., Akhavah A., Maraghechi H., Rajabipour F. (2013): How does fly ash mitigate alkali-silica reaction (ASR) in accelerated mortar bar test (ASTM
C1567). Cement and Concrete Composites, 37, 143-153. doi: 10.1016/j.cemconcomp.2012.11.004

24. Malvar L.J., Lenke L.R. (2005). Minimum Fly Ash Cement Replacement to Mitigate Alkali Silica Reaction. in: World of Coal Ash (WOCA). pp.1-12.

25. Malvar L.J., Cline G.D., Burke D.F., Rollings R., Sherman T., Greene J. (2001). Alkali-Silica Reaction Mitigation. State-of-the-Art. Technical Report TR 2195-SHR. Naval Facilities Engineering Service Center. Avaible online: https://apps.dtic.mil/dtic/tr/fulltext/u2/a526563.pdf

26. RILEM (2015). Recommended Test Method: AAR-2: Detection of potential alkali reactivity - Accelerated mortar-bar test method for aggregates.

27. ASTM C 1567-13 (2013). Standard Test Method for Determining the Potential Alkali-Silica Reactivity of Combinations of Cementitious materials and Aggregate (Accelerated Mortar-Bar Method).

28. Malvar L.J., Lenke L.R. (2006): Efficiency of Fly Ash in Mitigating Alkali-Silica Reaction Based on Chemical Composition. ACI Materials Journal, 103(5), 319-326.

29. Jensen V., Fournier B. (2000). Influence of different procedures on accelerated mortar bar and concrete prism tests: assessment of seven Norwegian alkali-reactive aggregates. in: Proceeding of the $11^{\text {th }}$ International Conference on Alkali-Aggregate Reaction in Concrete. Quebec City, Canada. pp. 345-354.

30. A-TC 106-2 - Detection of potential alkali-reactivity of aggregates - The ultra-accelerated mortar-bar test. (2000). Materials and Structures, 33, 283-293.

31. Alaejos P., Lanza V., Bermúdez M.A., Velasko A. (2014): Effectiveness of the accelerated mortar bar test to detect rapid reactive aggregates (including their pessimum content) and slowly reactive aggregates. Cement and Concrete Research, 58, 13-19. doi: 10.1016/j.cemconres. 2014.01.001

32. RILEM (2015). Recommended Test Method: AAR-4.1. Detection of potential alkali reactivity $-60^{\circ}$ test method for aggregates combinations using concrete prisms.

33. Owsiak Z. (2007): Testing alkali-reactivity of selected concrete aggregates. Journal of Civil Engineering and Management, 13(3), 201-207. doi: 10.1080/13923730.2007. 9636438

34. Raado L.M., Tuisk T., Rosenberg M., Hain T. (2011): Durability behaviour of Portland burnt oil shale cement concrete. Oil Shale, 28(4), 507-515. doi: 10.3176/oil.2011. 4.04

35. Raado L.M., Hain T., Liisma E., Kuusik R. (2014): Composition and properties oil shale ash concrete. Oil Shale, 31(2), 147-60. doi: 10.3176/oil.2014.2.05

36. Ahmed T., Burley E., Ridgen S., Abu-Tair A.I. (2003): The effect of alkali reactivity on the mechanical properties of concrete. Construction and Building Materials, 17, 123-144. doi: 10.1016/S0950-0618(02)00009-0

37. Swamy R.N., Al-Asali M.M. (1988): Engineering properties of concrete affected by alkali-silica reaction. ACI Materials Journal, 85, 367-374.

38. Yurtdas I., Chen D., Hu D.W., Shao J.F. (2013): Influence of alkali silica reaction (ASR) on mechanical properties of mortar. Construction and Building Materials, 47, 165-174. doi: 10.1016/j.conbuildmat.2013.04.046 